\title{
Nominal Interest Rates and Stationarity
}

\author{
Mario Cerrato*, Hyunsok Kim*1 and Ronald MacDonald* \\ University of Glasgow, Department of Economics, Adam Smith building.
}

May 25, 2010

${ }^{1}$ Hyunsok Kim University of Glasgow, Department of Economics, Adam Smith building (E-mail: h.kim.3@research.gla.ac.uk); Mario Cerrato (E-mail: m.cerrato@lbss.gla.ac.uk) and Ronald MacDonald (E-mail: r.macdonald@lbss.gla.ac.uk). We would like to thank Karim Abadir for his helpful comments and suggestions. 


\begin{abstract}
This paper investigates the (break) stationarity null hypothesis using data for 25 interest rates with different maturities and risk characteristics in Canada and the US. In contrast to a large part of the literature, this paper reports strong empirical evidence in favour of the null hypothesis of stationarity for the interest rate series.
\end{abstract}




\section{Introduction}

Nominal interest rates of different interest rate maturities are often found to be nonstationary, (Campbell and Clarida (1987); Newbold et al. (2001)), a result which has important implications for investment decisions and asset pricing models. For example, Gaussian interest rates models are very popular amongst practitioners and they hypothesise that interest rates are mean reverting, which seems at odds with the empirical evidence. However, most of the empirical papers that report nonstationary interest rates use standard linear econometric methods ${ }^{1}$. Such methods are questionable since these studies, generally, use very long time series in which structural breaks may have occured. In this paper we use a battery of recently developed unit root tests for (multiple) structural breaks and a new dataset consisting of twenty-five short-long nominal interest rates for the US and Canada. We show significant empirical evidence that interest rates (of different maturities) are indeed stationary around a structural break. Our finding of stationary nominal interest rates has important implications for testing, for example, the Fisher effect and term structure relationships, since it invalidates the use of cointegration methods, the approach generally used in this context, to test such relationships

\section{$2 \quad$ Econometric Methodology}

The transition functions $S_{t}(\theta)$ (with $\theta$ being a set of parameters to be estimated) considered in previous structural break models are given in Table (1)where $\delta=1$ is consistent with the logistic function ${ }^{2}$.

The structural change with logistic smooth transition (hereafter LSTR) is the one considered in Leybourne et al. (1998), where the time of the transition is determined by $c$, while its speed is determined by the parameter $\gamma$.

Since the logistic function-based models are unable to capture more than one

\footnotetext{
${ }^{1}$ Newbold et al (2001) being one of the few exceptions.

${ }^{2}$ Refer to Cerrato et al. (2010) for a complete description of these transition functions and tests.
} 


\begin{tabular}{l|l|l}
\hline \hline \multicolumn{1}{c|}{ Model } & \multicolumn{1}{|c|}{ Transition Function: $S_{t}(\theta)$} & Parameter: $\theta$ \\
\hline LSTR & {$[1+\exp \{-\gamma(t-c T)\}]^{-1}$} & $\gamma, c$ \\
ESTR & $1-\exp \left[-\gamma^{2}(t-c T)^{2}\right]$ & $\gamma, c$ \\
Asym ESTR & $1-\exp \left[-I_{t} \gamma_{1}^{2}(t-c T)^{2}-\left(1-I_{t}\right) \gamma_{2}^{2}(t-c T)^{2}\right]$ & $\gamma_{1}, \gamma_{2}, c$ \\
Sym K-STR & {$\left[1+\exp \left\{-\gamma^{2}\left(t-c_{1} T\right)^{2}\right\}\right]\left[1-\exp \left\{-\gamma^{2}\left(t-c_{2} T\right)^{2}\right\}\right]-1$} & $\gamma, c_{1}, c_{2}$ \\
Asym K-STR & {$\left[1+\exp \left\{-\gamma_{1}^{2}\left(t-c_{1} T\right)^{2}\right\}\right]\left[1-\exp \left\{-\gamma_{2}^{2}\left(t-c_{2} T\right)^{2}\right\}\right]-1$} & $\gamma_{1}, \gamma_{2}, c_{1}, c_{2}$ \\
\hline \hline
\end{tabular}

Table 1: Functions for Structural Change

break, Sollis (2005) extends the model by considering an exponential smooth transition (hereafter ESTR) and asymmetric exponential smooth transition (hereafter Asymmetric ESTR). This is asymmetric around the time of the transition $c T$. The value of $S_{t}(\theta)$ depends on the value of the parameter $\gamma$ and when $t=c T$, transition function $S\left(y_{t-d}, \theta\right)$ takes converges to zero. Cerrato et al (2010) propose an alternative transition function which they call K-STR. This transition function is able to capture structural changes taking place around long-run equilibrium path.

The transition functions are compared in Figure (1). The LSTR function only considers a single break whereas the ESTR function considers multiple breaks. The asymmetric ESTR suggested by Sollis (2005) has similar properties as the ESTR but it allows asymmetric scale parameters, $\gamma_{1}$ and $\gamma_{2}$ where $I_{t}=1$ if $(t-c T) \leq 0$ and 0 otherwise. The transition function $S_{t}(\theta)$ is also bounded from 0 to 1 when the $\gamma_{1}$ and $\gamma_{2}$ are sufficiently large values and if $\gamma_{1} \neq \gamma_{2}$ the speed of transition is asymmetric either side of the mid-point $c T$.

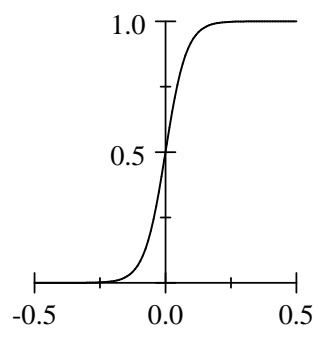

LSTR

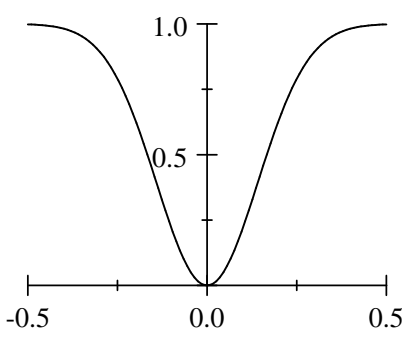

ESTR

Figure 1: Simulation for the LSTR and ESTR 


\section{Empirical Results}

The dataset used in this study is unique, consisting of 25 monthly Canadian and US interest rates of different maturity and risk spanning the period 1985:01 to 2004:04. For the Canadian rates, it consists of T-bill rates of different maturities, government bonds and Scotia indices for yields on corporate bonds. The US rates consist of T-bills with different maturities, government bond yields, commercial paper and yields on corporate AAA and BAA rated bonds. The data are taken from Moon and Perron (2007). Since the 1980s, the perception of the output-inflation tradeoff changed. For example, the Federal reserve with Alan Greenspan at the helm, devoted more attention to keeping a low inflation level than in the past since such a policy, combined with the larger predictability of monetary policy, contributed to making the economic environment more stable. Indeed, large parts of the literature claim that monetary policy in the US had not experienced any sort of permanent structural break since the late $1970 \mathrm{~s}^{3}$. Is this, however, borne out by the evidence?

We apply the econometric methodologies presented above. Furthermore, we also use the K-STR test suggested in Cerrato et al. (2010). The empirical results are reported in the table below. There is a very strong evidence of stationarity when the ESTR is used. The test shows that both short and long term interest rates in Canada are stationary. Furthermore, significant evidence of stationarity is also detected in the case of short and long term interest rates in the US. The US short term interest rates is stationary regardless of the econometric methodology used. This result is consistent with Newbold et al. (2001) which finds short-term interest rates in the US during the period 1890-1934 as stationary.

The table below shows the break dates for the interest rate series which were found stationary using the Sollis test ${ }^{4}$. In some cases the break date was estimated

\footnotetext{
${ }^{3}$ That is policy rue has not changed much since the post WWII experience (see Bernanke and Mihov, 1998 amongst the others). Furthermore, the Canadian policy of shift towards zero inflation in Februart 1988 may have also caused structural breaks.

${ }^{4}$ We have selected the Sollis test since it is the test which shows more evidence of stationarity.
} 


\begin{tabular}{|c|c|c|c|c|c|c|c|c|}
\hline \multicolumn{9}{|c|}{ Monthly (1985 - 2004) } \\
\hline \multirow[b]{2}{*}{ Country } & \multicolumn{2}{|r|}{ LSTR } & \multicolumn{2}{|r|}{ ESTR } & \multicolumn{2}{|c|}{ Sym K-STR } & \multicolumn{2}{|c|}{ Asym K-STR } \\
\hline & $k$ & $t_{L S T R}$ & $k$ & $t_{E S T R}$ & $k$ & $t_{S}^{A}$ & $k$ & $t_{A S}^{A}$ \\
\hline & & & \multicolumn{4}{|c|}{ Canadian rates } & & \\
\hline 1 month & 11 & -3.5969 & 12 & $-4.2597^{* *}$ & 12 & -1.4024 & 9 & -2.5257 \\
\hline 3 month & 11 & -3.5535 & 12 & -3.7338 & 9 & -2.1828 & 9 & -2.4727 \\
\hline 6 month & 10 & -3.5755 & 2 & -3.6740 & 11 & -1.0917 & 10 & -3.1454 \\
\hline 1 year & 10 & -3.4225 & 2 & $-4.1913^{* *}$ & 10 & -2.2062 & 10 & -3.0509 \\
\hline 2 years & 2 & -3.4747 & 2 & $-4.7004^{* *}$ & 1 & -1.1062 & 2 & -3.1862 \\
\hline 3 years & 1 & -3.6427 & 2 & $-4.6089^{* *}$ & 1 & -1.3187 & 1 & -3.3684 \\
\hline 5 years & 1 & -3.5240 & 3 & $-4.6285^{* *}$ & 3 & -2.0708 & 3 & -2.9268 \\
\hline 7 years & 0 & -3.6022 & 0 & $-4.7385^{* *}$ & 12 & -1.8826 & 0 & -2.7829 \\
\hline 10 years & 12 & -3.8180 & 1 & $-4.8208^{* * *}$ & 12 & -2.0279 & 0 & -2.3533 \\
\hline 1-m com.paper & 11 & -3.7381 & 12 & $-3.9020^{*}$ & 9 & -2.1829 & 11 & -2.8551 \\
\hline 3-m com.paper & 11 & -3.6322 & 11 & $-4.8361^{* * *}$ & 9 & -2.2129 & 9 & -2.8768 \\
\hline 1-m bank.acc. & 11 & -3.7054 & 11 & $-5.0982^{* * *}$ & 9 & -2.1644 & 9 & -2.6649 \\
\hline Long corporate & 12 & -3.5923 & 0 & $-3.8644^{*}$ & 12 & -1.7123 & 12 & -0.9741 \\
\hline Mid corporate & 1 & -3.3048 & 0 & $\begin{array}{l}-4.0469^{*} \\
\text { US rates }\end{array}$ & 9 & -1.5129 & 1 & -0.8860 \\
\hline 3 month & 11 & $-4.3153^{* *}$ & 11 & $-4.3153^{* *}$ & 11 & $-4.3115^{* *}$ & 11 & $-4.2667^{* *}$ \\
\hline 6 month & 10 & $-4.0584^{*}$ & 11 & $-4.0098^{*}$ & 10 & -3.2293 & 1 & -1.4697 \\
\hline 1 year & 12 & -2.8722 & 12 & -1.9203 & 12 & -2.7608 & 12 & -2.7446 \\
\hline 2 years & 9 & -2.9590 & 10 & -2.4653 & 9 & -3.2371 & 9 & -3.2224 \\
\hline 3 years & 11 & $-4.9474^{* * *}$ & 8 & $-5.1829^{* * *}$ & 11 & $-4.5891^{* *}$ & 11 & $-4.6484^{* *}$ \\
\hline 5 years & 1 & -3.1292 & 9 & -3.3262 & 9 & -3.2367 & 9 & -3.2205 \\
\hline 7 years & 9 & -3.6300 & 9 & -3.7416 & 9 & -3.3787 & 9 & -3.3539 \\
\hline 10 years & 9 & -2.8731 & 12 & -2.6786 & 9 & -2.5094 & 9 & -2.4978 \\
\hline 1-m com.paper & 9 & $-4.2350^{* *}$ & 12 & $-4.5695^{* *}$ & 9 & -3.7990 & 9 & -3.7666 \\
\hline AAA & 9 & -3.0351 & 0 & -2.7621 & 9 & -3.0389 & 9 & -3.0338 \\
\hline $\mathrm{BAA}$ & 9 & $-4.4186^{* *}$ & 11 & $-4.2611^{* *}$ & 9 & $-4.0263^{*}$ & 9 & $-3.9854^{*}$ \\
\hline
\end{tabular}

Table 2: Estimated Results for monthly Canadian and US interest rates 


\begin{tabular}{|c|c|c|c|}
\hline \multicolumn{4}{|c|}{ Monthly (1985 - 2004) } \\
\hline \multicolumn{4}{|c|}{ ESTR } \\
\hline \multicolumn{2}{|c|}{ Canadian rates } & \multicolumn{2}{|c|}{ US rates } \\
\hline & break date & & break date \\
\hline 1 month & 1986.10 & 3 month & 2002.06 \\
\hline 1 year & 1988.10 & 6 month & \\
\hline 2 years & & 3 years & 1990.02 \\
\hline 3 years & 1988.04 & 1-m com.paper & \\
\hline 5 years & & BAA & \\
\hline 7 years & 1999.06 & & \\
\hline 10 years & 1989.07 & & \\
\hline 1-m com.paper & 1989.04 & & \\
\hline 3-m com.paper & & & \\
\hline 1-m bank.acc. & 1987.04 & & \\
\hline Long corporate & & & \\
\hline Mid corporate & 1988.12 & & \\
\hline
\end{tabular}

Table 3: Break date of ESTR estimates

as taking place outside the sample data used, and therefore not computed ${ }^{5}$. The Canadian economy was hit hard by the recession of the early 1980s, with interest rates, unemployment and inflation being higher than in the United States. During the middle of the 1980s, the economy recoved sharply and Canada's economic growth was the highest of any OECD country. The break dates for Canada between 19861989 may be driven by this economic event. On the other hand the 2002 break data for 3-months US T-Bill rates may capture the effect of the recession which started in 2001.The recovery was hesitant until the end of the war in Iraq.

\section{Conclusion.}

In this paper we apply the latest structural break econometrics to identify the presence of structural breaks in 25 interest rates series of different maturity and risk. We show strong evidence of structural breaks for the majority of time series considered. We also report the approximate break dates using the exponential transition function. Our analysis suggests that Canadian interest rates were highly affected by

\footnotetext{
${ }^{5}$ Note that, in this case, the transition function is exponential and not logistic.
} 
the recession of the early 1980s, while there is clear evidence that short term Treasury rates were affected by the 2001 recession in the US. The presence of structural breaks in the short term rates in Canada and the US are new results which have not yet been reported in the literature, and they suggest that care should be taken when applying contegration based relationships to various interest parity conditions, such as term structure conditions and the Fisher effect. 


\section{References}

Bernanke, B. S. and I. Mihov (1998). Measuring monetary policy. The Quarterly Journal of Economics 113, 869-902.

Campbell, J. Y. and R. H. Clarida (1987). The term structure of euromarket interest rates. Journal of Monetary Economics 19, 25-44.

Cerrato, M., H. Kim, and R. MacDonald (2010). Equilibrium exchange rate determination and multiple structural changes. University of Glasgow Dept. of Economics Discussion Papers 2010-14.

Leybourne, S. J., P. Newbold, and D. Vougas (1998). Unit roots and smooth transitions. Journal of Time Series Analysis 19, 83-97.

Moon, H. R. and B. Perron (2007). An empirical analysis of nonstationarity in a panel of interest rates with factors. Journal of Applied Econometrics 22, $383-400$.

Newbold, P., S. Leybourne, R. Sollis, and M. E. Wohar (2001). US and UK interest rates 1890-1934 new evidence on structural breaks. Journal of Money Credit and Banking 33, 235-250.

Sollis, R. (2005). Evidence on purchasing power parity from univeriate models: The case of smooth transition trend-stationarity. Journal of Applied Econometrics 20, 79-98. 